\title{
VIRTUD Y VICIO DEL OBRERO EN LA ESPAÑA DEL SIGLO XIX (I)
}

\author{
Laura Casas Díaz \\ Profesora asociada de Historia del Derecho y las Instituciones. \\ Universitat Autònoma de Barcelona
}

\begin{abstract}
El presente artículo es una primera parte que persigue exponer, de forma breve, los vicios morales de la clase obrera recogidos por los Informes obtenidos por el Cuestionario de la Comisión de Reformas Sociales que pueden ser con concretados en la prostitución y su influencia, la delincuencia y actitudes amorales como la embriaguez, el juego, el concubinato y los malos tratos a las mujeres.

This article is a first part that seeks to expose, briefly, the moral vices of the working class gathered by the Reports obtained by the Commission's questionnaire that may be concretized in prostitution and its influence, crime and amoral attitudes such as drunkenness, gambling, concubinage and mistreatment of women.
\end{abstract}

Title: Virtue and vice of the worker class in Spain's nineteenth century (I)

Palabras clave: Comisión de Reformas Sociales, moral, prostitución, delincuencia. Key words: Commission of Social Reforms, morality, prostitution, delinquency.

IUSLabor 2/2019, ISSN 1699-2938, p. 172-196

DOI. 10.31009/IUSLabor.2019.i02.11

\section{Sumario}

1. El infortunio y el ascenso a la virtud: análisis de la moralidad del obrero del siglo XIX

2. La Comisión de Reformas Sociales: Grupo VIII: Condición moral de la clase obrera

3. Parte primera: de la inmoralidad y el vicio

3.1. Embriaguez

3.2. Juego

3.3. Concubinato y malos tratos a la mujer

4. Prostitución

5. La delincuencia y el delincuente en la España del siglo XIX 
5.1. Estadísticas penitenciarias

5.2. Estadísticas judiciales y de criminalidad

6. Conclusiones

7. Bibliografía 


\section{El infortunio y el ascenso a la virtud: análisis de la moralidad del obrero del siglo XIX}

En la España del siglo XIX la moral era definida como las obligaciones, deberes y virtudes personales en orden a principios básicos de bondad espiritual y rectitud ${ }^{1}$. Había de ser considerado como falto de moral aquel que se alejara de los principios establecidos acerca del adecuado proceder y la honradez. Siguiendo esta premisa, aquellos que residían en los peldaños más bajos de la escala social, la clase obrera, eran maldecidos con ostentar la depravación y perdición propia de aquellos que no habían sido tocados por la fortuna.

El presente artículo persigue exponer, de forma breve, la imagen de la moralidad de la clase obrera proyectada por las respuestas al Cuestionario elaborado por la Comisión de Reformas Sociales, habiendo de ser concentrados en la prostitución y su influencia, la delincuencia y cuantas actitudes amorales fueran acarreadas por la miseria.

La instrucción que puede obtenerse de la realidad social de la España decimonónica permite mostrar una imagen real de todo aquello que la sociedad prefirió mantener oculta. Por este motivo este estudio, partiendo de la revisión de la Información Oral y Escrita recogida por el Cuestionario de la Comisión de Reformas Sociales, pretende profundizar en la realidad que las clases más olvidadas de la historia, aquellas silenciadas por el eco de los grandes nombres, hubieron de vivir, presentando una perspectiva enfocada desde lo más recóndito de la moral. De este modo, el presente trabajo constituye una primera etapa en el análisis de la moralidad del obrero en la España del siglo XIX. Un segundo análisis, inseparable del presente, habrá de ser desarrollado posteriormente, centrándose, esta vez, en la rectitud moral y las virtudes atribuidas a la clase obrera y a los medios que hubieran permitido, según los Informes analizados, sortear los escollos de la miseria y el vicio.

\section{La Comisión de Reformas Sociales: Grupo VIII: Condición moral de la clase obrera}

La Comisión de Reformas Sociales nace en virtud del Real Decreto de 5 de diciembre de 1883, a instancias del entonces ministro de Gobernación, Segismundo Moret y

\footnotetext{
${ }^{1}$ Mayordomo, A., "Bases para el estudio de la formación moral y de la civilidad a través de los textos escolares en la primera mitad del siglo XIX”, Historia de la Educación, Vol. 2, 1983, p. 55-65.

Los textos didácticos escolares de la primera mitad del siglo XIX hacen alusión a la moralidad, tanto en manuales generales como en libros de lectura. Ejemplo de ello es la definición de "moral" realizada por el Dr. Díaz de Rueda como "la ciencia que examina los deberes del hombre en general y en particular, según sus diferentes relaciones, para conseguir la felicidad en esta vida y en la otra" en DíAZ DE RUEDA, R., La Escuela de Instrucción primaria, Impr. De Cuesta y Compañía, Valladolid, 1855, p. 65.
} 
Prendergast, bajo el nombre de Comisión para el estudio de las cuestiones que le interesan a la mejora o bienestar de las clases obreras, tanto agrícolas como industriales, y que afectan a las relaciones entre capital y trabajo $^{2}$. La historia constituiría a la Comisión de Reformas Sociales como la primera medida de política social fruto del liberalismo ${ }^{3}$. Será el interés en el desarrollo de estudios sociológicos del grupo fundador lo que llevará a la creación del instrumento de estudio objeto del presente análisis. Junto a Moret y Prendergast, aparece, indisociable, Gumersindo de Azcárate, quien hubiera de ser el elegido para el desarrollo de las bases que habrían de dar lugar a un extenso Cuestionario de treinta y dos apartados y doscientas veintitrés preguntas que, por medio de un modelo de cuestionario abierto, había de constituir una aproximación a la realidad social de la clase obrera. El modelo empleado, de estructura abierta, permitía la obtención de respuestas cercanas a la cuestión social y a la sensibilización con la realidad de aquellos sin voz ${ }^{4}$. Como bien describe María Dolores de la Calle, el formato de "cuestionario abierto" permitía conocer la mentalidad y pensamiento, tanto de autor como de encuestado ${ }^{5}$. La constitución de comisiones locales y provinciales permitió la práctica de sesiones públicas en las que se recogió información Oral, información que se contendría en la memoria juntamente con los informes escritos recogidos, empero, no fue posible la obtención de información acerca de la pregunta objeto de análisis en todas las provincias, aunque el tamaño de la muestra es suficiente a fin de proceder a su estudio.

Las preguntas comprendidas entre los grupos $\mathrm{V}$ a XVII conjugan la misérrima condición económica de la clase obrera y las injustas condiciones de trabajo. Concretamente, el Grupo VIII, centrado en la condición moral de la clase obrera, es donde se halla la pregunta que da pie a las páginas presentes:

"52. la condición moral: Virtudes y vicios más comunes entre la clase obrera; $i$ los últimos son tradicionales ó de fecha reciente; espíritu de economía y de previsión, é influjo en el mismo de la existencia ó la falta de instituciones que lo

\footnotetext{
2 Álvarez, J., "La Comisión de Reformas Sociales: Intentos y realizaciones en De la beneficencia al bienestar social. Seminario de Historia de Acción Social, Madrid, Consejo de General de Colegios Oficiales de Diplomados en Trabajo Social y Asistentes Sociales, Editorial Siglo XXI, 1986; ElORZA, A. y IGLESIAS, M ${ }^{\mathrm{a}}$ C., "La fundación de la Comisión de Reformas Sociales", Revista de Trabajo, no 25, 1969, pp. 75-105; CASTILLO, S., "El reformismo en la Restauración: Del Congreso Sociológico de Valencia a la Comisión de Reformas Sociales", Estudios de Historia Social, n 30, 1984, p. 21-78.

${ }^{3}$ De La Calle Velasco, M ${ }^{a}$ D., "La Comisión de Reformas Sociales: de la represión al análisis de la conflictividad social", Studia Historica, vol. II, n 4, 1984, p. 13-41.

${ }^{4}$ Palacio Morena, J. I., La institucionalización de la reforma social en España (1883-1924). La Comisión y el Instituto de Reformas Sociales, Ministerio de Trabajo y Seguridad Social, Madrid, 1988.

${ }^{5}$ De La Calle Velasco, Ma D., La Comisión de Reformas Sociales 1883-1903: política social y conflicto de intereses en la España de la Restauración, Centro de publicaciones del Ministerio de Trabajo y seguridad Social, Madrid,1989.
} 
estimulen; la prostitución bajo el punto de vista de la mujer caída en ella, y su influjo en la moralidad de la clase obrera y en las relaciones de ésta con los demás; delincuencia y relación, dentro de cada grupo industrial, entre el número de delincuentes y el total de la clase.

No pudiendo proceder a un análisis pormenorizado de cada uno de los elementos expuestos en la información recogida, se ha seleccionado el estudio de los vicios más comunes entre la clase obrera, así como la prostitución y la delincuencia. La condición moral, como se desprende de la información recogida, resulta inescindible de la condición intelectual de la clase obrera, que se presenta como una de las causas del relajamiento moral, empero el presente estudio se centrará en las respuestas obtenidas acerca de la moralidad, reservando sus implicaciones con otras cuestiones tratadas en el Cuestionario, tales como la formación, para un estudio posterior ${ }^{6}$.

\section{Parte primera: de la inmoralidad y el vicio}

El análisis de los informes realizados por las Comisiones Provinciales y Locales de Reformas Sociales acerca de la pregunta 52 del Cuestionario presentan una imagen sombría de la clase obrera del último cuarto del siglo XIX español, una imagen eminentemente dibujada por los trazos de la acuciante miseria, pesada carga que la sobreexplotación que la industrialización y el cambio de modelo socioeconómico hubieron de llevar consigo.

De entre todos los reportes acerca de la moralidad de los obreros destaca, en especial, el informe del ingeniero jefe de las minas de Linares, información que pudiera considerarse manifiestamente sesgada por el cargo de quien firma, por cuanto subsume al colectivo minero como aquellos individuos mayormente privados de moral y fuente de todo género de vicios ${ }^{7}$. Del mismo modo, el tenor literal del Informe del clero de Santa María (Alicante) ${ }^{8}$ resalta de entre los informes y respuestas analizados, por cuanto

\footnotetext{
${ }^{6}$ Las referencias realizadas a lo largo del estudio pertenecen a la edición facsímil del centenario de 1983 con prólogo de Santiago Castillo, en adelante, Reformas Sociales, Información oral y escrita publicada de 1889 a 1893. Edición al cuidado de Santiago Castillo. Edición facsímil. Centro de Publicaciones Ministerio de Trabajo y Seguridad Social, Madrid, 1985.

7 “Las virtudes son escasas entre la clase obrera, principalmente entre los hombres de la minería, pues, aunque por naturaleza tengan algunas tendencias al bien y el respeto y consideración á sus semejantes, sus prácticas raras veces dan á conocer aquellos buenos sentimientos. Se ve en ellos egoúsmo y todo género de vicios, cuidan poco ó nada de sus hijos en su educación, instrucción y trato, maltratan á sus mujeres y abandonan a la familia. Lo que no se conoce en Linares es el robo. El obrero agrícola es menos vicioso que el obrero minero, más religioso y más unido á su familia, á la que guarda también más consideraciones. Entre uno y otro extremo se encuentran los demás obreros industriales y los albañiles, carpinteros y obreros de otros oficios" (Reformas Sociales, Tomo V, op.cit, p. 165).

${ }^{8}$ Reformas Sociales, Tomo IV, op.cit., p. 87.
} 
atribuye los vicios de la moral de la clase obrera a la perdida de fe, hecho que empuja al obrero a actuar de forma inmoral habida cuenta que su única percepción terrenal de la vida y la ausencia de más allá no le obligan a un proceder concorde a evitar el castigo divino. Reiterada es la mención de un grupo de vicios en los que se centrará el presente análisis: la embriaguez, el juego, el concubinato y los malos tratos a la mujer. Cuestiones escindidas constituirán la prostitución y las estadísticas de criminalidad. Empero, algunos vicios menores deben ser reseñados de presente, entre los que encontramos el lujo, la blasfemia y el lenguaje obsceno ${ }^{9}$ o, incluso, el consumo de tabaco. Asimismo, se procede a desarrollar breves corolarios acerca de la información presente en los Informes, destacando las interpretaciones e injerencias consideradas de mayor interés.

\subsection{Embriaguez}

En la sociedad del ochocientos español se perfila una manifiesta división de pensamiento acerca del consumo de alcohol. Liberales y federales republicanos, así como higienistas, ya clamaban a mediados del siglo XIX acerca de la gravedad de la adicción al alcohol y su influencia en las estadísticas de criminalidad ${ }^{10}$. Como apunta Francesc Freixa ${ }^{11}$ en su obra acerca de la adicción al alcohol en la España contemporánea, la voluntad de los políticos era reflejo de la arraigada cultura popular de "afición al vino", siendo esta causa de problemáticas familiares y motor de la pretendida escasa conciencia social de los obreros. Se pretendía que el obrero se alejara de bodegas y tabernas, abandonando tan malogrado caldo de vicio moral ${ }^{12}$. Empero, vanos eran los intentos de separar al obrero del vaso de vino cuando tan sutiles tentativas de desarraigo a la adicción eran superadas por presiones económicas, siendo un claro ejemplo la campaña promocional amparada por la Real Orden de 28 de abril de 1887 del Ministerio de Fomento, por la que se incluía un concurso en el que se otorgaban dos premios a quienes realizaran las mejores "Cartillas Vinícolas", convirtiéndose en un medio de propagación de la cultura vinícola ${ }^{13}$. Asimismo, la Real Orden incluía grandes ventajas

\footnotetext{
${ }^{9}$ Reformas Sociales, Tomo IV, op.cit., p. 469.

${ }^{10}$ Duran Ventosa, R., L'ivresse devant le Droit Penal, Imprenta A. López, Barcelona, 1890.

${ }^{11}$ FreIXA, F., "Perspectiva histórica de la problemática del alcohol en España", en TORRES HERNÁNDEZ, M. A. (Coordinador) et al., Historia de las adicciones en la España contemporánea, Gobierno de España, Ministerio de sanidad y consumo, 2009, p. 171-187.

${ }^{12}$ A tal efecto FreIXA, F., op.cit., recuerda que en la época el coma alcohólico, estado de coma causado por una sobredosis en la ingesta de alcohol, era denominado "difunto de taberna", denominación que manifiesta mediante el léxico la realidad histórica del momento.

${ }^{13}$ Alabanza clara al consumo del vino es el contenido de la obra premiada: “...vinicultura..., primera riqueza actual de nuestra patria...gratitud hacia el Gobierno...y la Sociedad...vitícola y Enológica”. FREIXA, F., op.cit.
} 
para los magnates vendimiadore ${ }^{14}$. Se alababan los beneficios del vino y se desinformaba a la población de sus afectos adversos en la salud ${ }^{15}$.

La realidad social del obrero se constituía como uno de los factores principales que incidían en esta problemática. Con la industrialización llegaría la sobreexplotación de la mano de obra que arrastró consigo cambios en la condición de vida del obrero. Una de ellas fue el consumo de alcohol, remedio para soportar las duras jornadas de trabajo ${ }^{16}$. El alcohol permitía alejarse de los grises tintes de las fábricas, de la necesidad y de la imperiosa miseria de los sectores industriales y agrícolas. Clara muestra de ello es la respuesta obtenida en la información escrita de Ávila, donde se anuncia que los vicios más salientes de la clase obrera en esta provincia eran la embriaguez y el juego, vicios que, si bien eran reportados desde muy antiguo, habían experimentado un aumento notable desde las obras del ferrocarril del Norte ${ }^{17}$.

Si bien el consumo de alcohol y, en su mayor exponente, la adicción a éste, han de ser consideradas como una consecuencia y una necesidad a la precaria situación laboral de la clase obrera, no faltaron quienes, desde posiciones de poder, clamaran por una respuesta acorde a la bajeza moral y la tendencia al vicio y la haraganería del obrero, al que le era reiteradamente atribuido la ambición del lujo y el placer anhelando conseguir, sin que mediara esfuerzo alguno, los frutos de la laboriosidad, pensamiento que impregna, precisamente, la mayor parte de las respuestas obtenidas en los distintos informes analizados. Ello lleva a la ausencia de asombro cuando la embriaguez es reportada como uno de los vicios más destacados en las respuestas del Cuestionario, siendo ésta referida como vicio de la moral por la mayoría de las Comisiones Provinciales, véanse Madrid, La Coruña, Linares, Valencia, Asturias, Palencia, Alcoy, Cáceres, Badajoz y Burgos ${ }^{18}$. Muestra de ello es el discurso que traería consigo, en 1904, la promulgación de la Ley de descanso dominical ${ }^{19}$. Es importante para el presente trabajo el concepto de "taberna", distinto al de "casa de comidas". El Real

\footnotetext{
${ }^{14}$ Martínez Montalvo, M. C., "La elaboración del vinagre en el siglo XIX. Discordia y enfrentamiento químico-biológico", Historia de las ciencias y de las técnicas, vol. 2, 2004, p. 687-702.

${ }^{15}$ FREIXA, F, op.cit.

16 "Todo exceso en la bebida y todo vicio desordenado produce debilidad para el trabajo y prematura vejez, aparte de otros inconvenientes que sumen al pobre trabajador en la más negra desventura" PASCUal Pastor, F., "Antecedentes históricos de las Adicciones. Del siglo XIX hasta 1940”, en TORRES HERNÁNDEZ, M. A. (Coordinador) et al., Historia de las adicciones en la España contemporánea, Gobierno de España, Ministerio de sanidad y consumo, 2009, p. 15.

${ }^{17}$ Reformas Sociales, Tomo IV, op.cit., p. 216.

${ }^{18}$ ELORZA, A. y IGLESIAS, M ${ }^{\text {a }}$ C., Burgueses y Proletarios. Clase obrera y reforma social en la Restauración (1884-1889), Editorial Laia, Barcelona, 1973, p. 127-128.

${ }^{19}$ Ley de descanso dominical de 3 de marzo de 1904, en la Gaceta no 64 de 4 de marzo, así como el Reglamento de 19 de agosto de 1904 para la aplicación de la Ley sobre descanso dominical en la Gaceta de 22 de agosto.
} 
Decreto de 19 de abril de 1905, Reglamento para la aplicación de la ley sobre descanso dominical, definía las tabernas dentro del Capítulo dedicado a las excepciones al descanso dominical:

"A este efecto se entiende por taberna toda tienda, casa pública ó establecimiento donde se vende al por menor principalmente vino ó cualquier otra bebida alcohólica, aunque por excepción se expendan artículos de comer ó de otra especie, y por casa de comidas, la que principalmente se dedica á servir comida y no expende más bebida que la que comiendo se consume" 20 .

De cuantas protestas se derivaron de la tan perseguida Ley destaca, en este punto, la consideración acerca de las tabernas y el malévolo influjo de éstas en la moral del proletariado, habiendo de ser consideradas como "lugares de vicio" que en ningún caso prestaban servicios de imperante necesidad. Caso distinto es el que se configura en Bilbao, donde la embriaguez se considera como escasa, atribuyéndose a la mala calidad de las bebidas a las que puede tener acceso el obrero y a la ausencia de costumbre. En el patrón del consumo de alcohol puede dibujarse una separación entre las distintas zonas peninsulares, evidenciándose en las zonas rurales una preeminencia en el consumo de vino y aguardientes, manteniendo pautas tradicionales de consumo, distinción que favorece la tesis acerca del alcohol como medio de evasión del obrero ${ }^{21}$. También resulta de interés la relación que se establece entre embriaguez y comisión delictiva en el Informe de Enrique Serrano Fatigati ante el Ateneo de Madrid: "El estado de embriaguez predispone aquí más que en otros países a la comisión de delitos".

Al consumo de alcohol y la embriaguez ha de añadirse un vicio menormente reportado, pero de relevancia a efectos del presente estudio: el consumo de tabaco. Es la especial mención recogida en Sueca (Valencia) la que hace necesario su análisis: "El vicio más común entre el menor número de individuos pertenecientes á la referida clase es el de las bebidas alcohólicas, además del continuado uso del tabaco, que es también muy general en el resto de la misma" 22 .

Las boticas de América y Europa, durante el siglo XIX, ofrecían a la población remedios derivados de drogas conocidas de antaño que en la España decimonónica comenzaron a producir contraindicaciones. Entre todas ellas destacan el alcohol y el tabaco $^{23}$. En el siglo XIX se produjo un aumento en el consumo del tabaco ello debido

\footnotetext{
${ }^{20}$ Artículo 7 del Real Decreto de 19 de abril de 1905, Reglamento para la aplicación de la Ley sobre descanso dominical publicado en la Gaceta 22 de abril.

${ }^{21}$ Pascual Pastor, F., op. cit.

${ }^{22}$ Reformas Sociales, Tomo III, op. cit., p.369.

${ }^{23}$ Pascual Pastor, F., op.cit.
} 
al crecimiento demográfico y de la riqueza, factores que comportaron un aumento de este producto de lujo, motivo por el cual la respuesta obtenida en Sueca, que pudiera quedar relegada en un simple comentario, se constituye, por el contrario, en un modelo de las circunstancias socioeconómicas de la España decimonónica.

\subsection{Juego}

El juego es apuntado como vicio en gran parte de los Informes, destacándose Valencia, Alcoy, Navarra, Cáceres y Badajoz, Linares, Oviedo, La Coruña y Ávila:

"El (vicio) del juego es bastante común, en los pueblos especialmente, pero alcanza á todas las clases. El de la lotería (desgraciadamente nacional) está muy generalizado, y más aún entre el pueblo las rifas clandestinas"24 "pero los vicios son numerosos en las clases sociales en general; hay quien juega hasta la camisa; quien se empeña por dar dinero á la Lotería del Gobierno llamada nacional y hacerse rico" 25 .

El Código Penal de 1870 dedicaba su Título VI a "los juegos y rifas". Así, por medio de los artículos 358, 359 y 360 se castigaba a "banqueros y dueños de casas, de juego, suerte envite o azar" a penas de arresto mayor y multa, con agravantes en caso de reincidencia. Del mismo modo se condenaba a quienes vendieran o expidieran billetes de loterías o rifas no autorizadas, produciéndose el decomiso de cuántos instrumentos y dinero se derivara de tales actividades. En la Tabla siguiente se relaciona el porcentaje de delitos cometidos bajo los tipos descritos entre 1883 y 1885 :

Tabla 1. Porcentaje de delitos "de los Juegos y rifas" 1883-1885

\begin{tabular}{|c|c|c|c|}
\hline & 1883 & 1884 & 1885 \\
\hline Juegos y rifas & $0,34 \%$ & $0,13 \%$ & 0,1 \\
\hline
\end{tabular}

Fuente: Elaboración propia a partir del Anuario estadístico de 1888 del Instituto Nacional de Estadística (INE)

Pese atender al hecho que las estadísticas refieren a quienes ostentaren locales dedicados a la celebración de las actividades relacionadas con el juego de carácter ilegal y no a quienes participaran en las actividades que tuvieran lugar intramuros, hablamos de un porcentaje muy bajo de casos, siendo ejemplo que en 1885 , año que presenta una menor incidencia, sólo alcanza el $0,1 \%$ de los delitos reportados para ese año. Sin embargo, pese a la escasa incidencia que esta tipología delictiva pudiera parecer

\footnotetext{
${ }^{24}$ Reformas Sociales, Tomo III, op.cit., p. 86.

${ }^{25}$ Reformas Sociales, Tomo IV, op.cit., p. 286.
} 
ostentar en el grueso de los delitos perpetrados para el lapso de tiempo de referencia, hay que reiterar que éstos atienden al hecho de regentar estos establecimientos, no a participar en sus actividades que, como se detrae de las respuestas al Cuestionario, era frecuente. Además, la cifra negra, refiriéndonos al volumen de delitos que escapan al control de las estadísticas, es un factor ineludible cuando de tratar índices de criminalidad se refiere, cifra que en el último cuarto del siglo XIX ha de presumirse elevada.

Como muestra de las respuestas recogidas que refieren al juego como vicio de la moral del obrero, el Informe del Ayuntamiento de Alcoy expone que, si bien la clase obrera se caracteriza por su laboriosidad, algunos individuos, especialmente en época de celebración de fiestas populares, se dejan dominar por "la pasión del juego"26. De nuevo, este estamento puede relacionarse con cuanto se ha reportado acerca de la ley de descanso dominical, que ya referenciábamos al hablar de la embriaguez y es que había que considerarse que el obrero era corrompido en su tiempo libre por cuanto el libre albedrío conllevaba a una inevitable caída en actitudes moralmente reprochables.

\subsection{Concubinato y malos tratos a la mujer}

Aparece el concubinato como uno de los vicios atribuidos a la clase obrera por los distintos informes examinados. Pese no ser usual su referencia, es necesario que éste sea tenido en cuenta por la lectura social que de su referencia se detrae. Reviste especial interés la referencia realizada en el Informe de Badajoz:

"El concubinato, condenado por todas las clases sociales, es muy raro entre los obreros y casi siempre motivado por dificultades para legitimar la unión, tales como falta de recursos para sufragar los gastos en la Vicaria y Juzgado municipal, para obtener dispensa los parientes en grados remotos, pues los próximos no piensan jamás en uniones legitimas ni ilegitimas" 27.

Nos hallamos ante una clase social que dispone de escasos medios económicos y que ha de renunciar, entre otros lujos y privilegios, a formalizar su unión de pareja por los medios tolerados y preferidos por la moral imperante. La pobreza es la causa principal del concubinato. En el mismo informe, en Badajoz, se hace clara alusión al hecho que éste pudiera ser eliminado por medio del establecimiento de gratuidad en la inscripción en el Registro civil de la clase obrera cuando a estos les hubieran sido facilitados otros beneficios análogos a causa de su pobreza, hecho que habría de ser reproducido por las autoridades eclesiásticas por cuanto el matrimonio canónico producía los mismos

\footnotetext{
${ }^{26}$ Reformas Sociales, Tomo IV, op.cit., p. 77.

${ }^{27}$ Reformas Sociales, Tomo IV, op.cit., p. 331.
} 
efectos que el matrimonio civil, más cuando se siguiera constituyendo como única legalidad de las uniones matrimoniales ${ }^{28}$.

Los malos tratos a las mujeres son recogidos en múltiples provincias. Así, ya veníamos apuntando la opinión expuesta en Linares, donde se presenta a una clase minera sumida en el vicio que profiere malos tratos a sus esposas que, por el contrario, son ejemplo de virtud. También se hace eco del maltrato en La Coruña: "vicios más comunes en otros son la embriaguez, la grosería del lenguaje, la holganza, el abandono de los hijos y el maltrato a las mujeres" 29 .

\section{Prostitución}

La prostitución es otro de los elementos destacados en la pregunta 52 del Cuestionario, siendo ésta objeto de especial mención en Madrid, Valencia, Bilbao, Linares, Oviedo, La Coruña, Alcoy, Ávila, Cáceres y Badajoz ${ }^{30}$. Desde una perspectiva legal, el Título X del Código Penal de 1870, que mantenía inalterada la rúbrica de los delitos contra la honestidad del código de 1848, recogía los denominados "Delitos contra la honestidad"31. Dichos preceptos, como su nombre indica, pretendían proteger la honestidad en sí misma, más allá de ofrecer una protección a la persona, sino que se trataba de una legislación orientada a la protección de concepciones morales ${ }^{32}$. En la legislación penal de la España decimonónica sólo se tipificaba como ilícito penal la prostitución de menores. La prostitución adulta quedaba así sin tipificar, entendiéndose por parte del legislador como insuficientemente lesiva para el bien jurídico protegido, la sociedad $^{33}$. Esta ausencia de estadísticas o censos dificultan el cómputo de la incidencia que tuvo la prostitución en el último cuarto del siglo XIX cuando a la prostitución adulta nos referimos, empero, las jóvenes comenzaban a trabajar a edades muy tempranas, hecho que evidencia la voluntad de la regulación de dicha edad con la Ley Benot de 24 de julio de 1873.

\footnotetext{
${ }^{28}$ Reformas Sociales, Tomo IV, op.cit., p. 345.

${ }^{29}$ Reformas Sociales, Tomo V, op.cit., p. 55.

${ }^{30}$ Sensu contrario, destacan como zonas que refieren poca incidencia de prostitución el Ferrol, Alcira, Ayora y Sueca.

${ }^{31}$ La prostitución bajo el punto de vista de la mujer caída en ella, y su influjo en la moralidad de la clase obrera y en las relaciones de ésta con los demás.

32 Santamaría Lambás, F., El proceso de secularización en la protección penal de la libertad de conciencia, tesis doctoral, Universidad de Valladolid, 1999.

${ }^{33}$ GaVilán Rubio, M., "Delitos relativos a la prostitución y a la trata de seres humanos con fines de explotación sexual. Algunas dificultades en la fase de instrucción", Anuario Jurídico y Económico Escurialense, vol. XLVIII, 2015, p. 103-130.
} 
Los artículos $458^{34}$ y 459 del Código Penal tipificaban el estupro y la corrupción de menores. De mayor interés para el presente trabajo es el tipo contenido en el artículo 459 , por el que se penaba con prisión correccional al que habitualmente o con abuso de autoridad o confianza promoviera o facilitara la prostitución o corrupción de menores de edad $^{35}$. En la España del siglo XIX el abuso sexual a menores no eran un fenómeno aislado, produciéndose éstos dentro y fuera del seno familiar ${ }^{36}$. La explotación laboral del menor tras la industrialización añadió al abuso laboral el abuso sexual dado que la miseria y la penosa condición de vida en la que se veían sumergidos las niñas y niños obreros en ocasiones les conducía a la prostitución ${ }^{37}$.

Las estadísticas obtenidas acerca de los delitos contra la honestidad para el período estudiado no permiten diferenciar entre tipos delictivos, disponiendo consiguientemente de unos valores absolutos que incluyen todos los tipos regulados en el capítulo reservado a tales delitos. Tales cifras oscilan entre el $1,10 \%$ y el $1,37 \%$ del total de delitos reportados entre los años 1883 y 1885, manifestando una tendencia al alza. Empero, esta ausencia de clasificación delictiva en las estadísticas ofrecidas por el Anuario de 1888 dificulta el análisis y la posibilidad de efectuar conclusiones claras acerca del fenómeno de la prostitución infantil. Prueba de la manifiesta ausencia de datos estadísticos es la información recogida en Valencia donde se pudieron computar únicamente 298 prostitutas inscritas en la ciudad de Valencia. De todas ellas, por datos provenientes de la sección de Higiene del Gobierno Civil, pueden computarse dos terceras partes del cómputo referido como pertenecientes a la clase obrera y, el tercio restante, a pertenecientes a las industrias domésticas o servicio doméstico ${ }^{38}$.

Las condiciones de vida de la clase obrera y su situación hacen de la prostitución un fenómeno que en ningún caso puede ser calificado como aislado. La mayor parte de las

\footnotetext{
${ }^{34}$ El elemento típico del estupro, regulado en el artículo 458, era el mantenimiento de relaciones sexuales con jóvenes mayores de doce años y menores de veintitrés, habiendo de ser este cometido por Autoridad pública, sacerdote, criado, doméstico, tutor, maestro o cualquiera fuera el encargado de la educación o guarda de la joven. En el párrafo segundo del referido precepto se preveía agravante en caso de que el estupro fuera cometido con hermanas o descendientes del autor, aunque la víctima fuera mayor de veintitrés años. Si mediara engaño en la perpetración del ilícito, también se preveía agravante.

${ }^{35}$ SÁEz MARTínez, G.J., "Aproximación histórica a los abusos sexuales a menores”, Eguzkilore, 2015, n 29, p. 137-170.

${ }^{36}$ Apunta SÁEZ MARTínEZ que la regulación penal mantenía la mentalidad penal del Antiguo Régimen, protegiendo así la honestidad más que la sexualidad de los menores. op.cit., p. 145.

${ }^{37}$ Refiere ALBó, R. en "La prostitución de los niños" que "la consecuencia directa de la miseria y de los malos tratos que recibían en el hogar, tengamos en cuenta que estos pobres niños prostituidos no han nacido para tales. La orfandad, los malos tratos del padre, de la madrastra; el malestar del hogar, la barraca, la miseria, el tener que luchar por la vida antes de tiempo, los ha lanzado a la calle" (ALBó, R., La prostitución de los niños, Proinfantia, $\mathrm{n}^{\circ}$ 155, Madrid, 1924, p. 438).

${ }^{38}$ Reformas Sociales, Tomo III, op.cit., p. 86-87.
} 
respuestas culpan a la miseria como causa principal de la prostitución. Suárez Casañ en 1895 hablaría de la prostitución en época contemporánea y proferiría como causa y fundamento de ésta la miseria, la falta de creencias religiosas y, relacionado con cuanto se ha descrito acerca del vicio del juego, los bailes públicos ${ }^{39}$.

En la Información oral de Alcoy se ofrece una interesante perspectiva: no es la mujer la culpable de caer en la práctica de la prostitución, sino que es el marido quien "se juega su jornal y que sume á la familia en la necesidad, es (él) quien la lanza en el camino de la prostitución" " ${ }^{40}$. Es una evidencia más de la distinción de clases, la riqueza de quien acude a ella y la miseria de quien la ofrece. No por ello sorprende la constatación que la mayor parte de las ejercientes de la prostitución proceden del sector fabril, en el que trabajaban conjuntamente obreros de ambos $\operatorname{sexos}^{41}$. La Memoria de la Comisión Provincial de Burgos incide en este aspecto, refiriendo que el trabajo de la mujer en fábricas o talleres influía en la moralidad de la mujer soltera, permitiendo, de este contexto estructural: "Desaparece lo más precioso de éstas, el pudor, se pisotea la moral, y la que había de ser más tarde buena esposa y madre le parece pesada la carga del matrimonio (...) pero es claro, tienen que trabajar para aumentar el haber de la familia y no ver el terrible fantasma del hambre" ${ }^{42}$.

La miseria se configura como el factor principal que da lugar a la prostitución decimonónica $^{43}$. Es la muestra de una sociedad sesgada que, como en el caso de Valencia, constituye una práctica extendida, tolerada por la población que, a su vez, no consentía su pública manifestación. Se evidencia así realidad de una sociedad que hace oídos sordos a aquello que no resulta de interés manifestar y es que la prostitución era mantenida por las clases enriquecidas, constituyéndose, por el contrario, como muestra última de la condición en la que se hallaba el proletariado ${ }^{44}$. A tal efecto resulta interesante el Informe de D. Antolin Santodomingo, de la Comisión Provincial de Ávila

\footnotetext{
${ }^{39}$ Véase la obra de SuÁREZ CASAÑ, V., La prostitución, Casa editorial Maucci, Barcelona, 1895.

${ }^{40}$ Reformas Sociales, Tomo IV, op.cit., p. 33.

41 "En resumen, el mayor peligro de este género para las obreras proviene de dos causas: el contacto habitual y diario con los obreros cuando trabajan en las mismas fábricas, y el domicilio fuera de su familia para aquellas cuyos padres ó parientes muy cercanos no residen en el punto que ellas han necesariamente de habitar" (Tomo III, p. 86-87).

${ }^{42}$ Reformas Sociales, Tomo IV, op.cit., p. 427.

${ }^{43}$ PAZ, O. y CASAS, L., "Presidio, castigo, prostitución: mujeres en el siglo XIX", Crítica Penal y Poder, $\mathrm{n}^{\circ} 15,2018$, p. 150-179.

${ }^{44}$ Reformas Sociales, Tomo IV, op.cit., p. 173: "D. Pascual Amat dijo que la prostitución revela doble inmoralidad en el hombre que prostituye que en la mujer prostituida; que proviene esta inmoralidad del exceso de recursos, la no necesidad de trabajar y la holganza, que escaseando en Ávila el trabajo y siendo por lo mismo muy buscado por el obrero, quien no cuenta con recursos sobrados, éste no va á la prostitución. D. Félix Antero, maestro sastre, dijo que la poquísima prostitución existente en Ávila está sostenida por las clases que tienen dinero."
} 
en la que se refiere a la ausencia de prostitución entre la clase obrera pero sí en las demás clases sociales ${ }^{45}$.

En la sesión de 19 de octubre de 1884, donde informó el Sr. Vives Mora, representante del Ateneo del Casino obrero de Valencia, se hace hincapié en el origen de la prostitución atendiendo al origen de la mujer caída en ella: por seducción y abandono en los supuestos de empeladas del hogar y ostentación del lujo en las obreras ${ }^{46}$. Esta referencia a la ostentación del lujo habrá de relacionarse con posteriores postulados que se analizarán a efectos del origen de las estadísticas criminales.

\section{La delincuencia y el delincuente en la España del siglo XIX}

La Comisión halló en su proceder un imperioso obstáculo: la falta de estadísticas, que no habrían de existir hasta tiempo después, hallándonos, por consiguiente, en la pretensión de esclarecer unos datos en un período preestadístico ${ }^{47}$. La fecha de las informaciones objeto de estudio van desde la segunda mitad de 1884 a junio de 1886. A fin de proceder a un estudio pormenorizado de la incidencia criminal del último cuarto del siglo XIX español y su efectiva correlación con los datos extraídos del Cuestionario, se ha procedido a analizar los índices criminales y penitenciarios del período comprendido entre 1883 y 1885 que ofrece el Anuario estadístico de 1888 publicado por el Instituto Nacional de estadística ${ }^{48}$.

Para una mayor concreción analítica se distinguirá entre estadísticas penitenciarias, incluyéndose en este apartado cuanta información haya podido ser obtenida de los establecimientos penitenciarios, y estadísticas judiciales, refiriéndonos al volumen de delitos enjuiciados por las distintas Audiencias.

\footnotetext{
${ }^{45}$ Reformas Sociales, Tomo IV, op.cit., p. 186.

${ }^{46}$ Reformas Sociales, Tomo III, op.cit., p. 172.

47 Precisa este apartado de una previa contextualización por cuanto se procederá a considerar delito aquellas acciones tipificadas por el Código penal vigente en el momento en que fueron elaborados los informes objeto de análisis. Asimismo, serán anunciadas conductas que, pese a no poder incluirse en el grueso de la criminalidad analizada habrán de ser tenidas en cuenta por ser consideradas como actos contrarios a la moral imperante.

${ }^{48}$ Los datos a los que se hará referencia en este apartado corresponden a los datos descritos en la "Reseña Geográfica y Estadística de España de 1888” del Fondo Documental del Instituto Nacional de Estadística.
} 


\subsection{Estadísticas penitenciarias}

El Real decreto de 1 de septiembre de $1879^{49}$ clasificaba los establecimientos penales atendiendo a las variables de sexo y tipo de condena. En primer lugar, se diferenciaba entre establecimientos eminentemente masculinos y, para las mujeres, cualesquiera que fuera su condena, ser reservaba la Casa-Correccional de Alcalá de Henares donde eran confinados también los delincuentes menores de veinte años, pues recordemos que a la mujer le era atribuido el mismo estatus jurídico que al menor de edad ${ }^{50}$.

Por lo que refiere al presidio masculino, éste se conformaba por tres clases, establecimientos de primera, de segunda y de tercera ${ }^{51}$, estableciéndose una clase diferenciada para aquellos condenados a cadena, reclusión y relegación perpetua ${ }^{52}$.

Son pocas las referencias específicas a los presidios halladas en la información recogida ${ }^{53}$. Empero, la Memoria de la Comisión Provincial de Burgos hace especial alusión a los establecimientos penitenciarios manifestando el "maligno influjo" de éstos en todos los oficios:

\footnotetext{
${ }^{49}$ El Real Decreto de 1 de septiembre de 1879 sería posteriormente reformado por el Real Decreto de 6 de noviembre de 1885, reforma motivada a causa de la distribución geográfica de los diecinueve establecimientos penales constituidos hasta entonces, constitución que no suplía las necesidades al planteamiento del juicio oral y que agravaba la condena de los penados, quienes eran, consiguientemente, obligados a recorrer amplias distancias, incidiendo así en su salud y en la agravación de los intereses públicos. A tal fin se dividió el territorio peninsular en cinco zonas a las que habría que añadir dos más, Baleares y Canarias. Así, a tenor ilustrativo, las penas de cadena y represión perpetuas pasarían a penarse en Ceuta, cualesquiera hubiera sido la Audiencia Sentenciadora. Fuente: fondo documental del Instituto Nacional de Estadística, Reseña geográfica y estadística de España 1888, establecimientos penales.

${ }^{50}$ Artículo 3 Real Decreto de 1 de septiembre de 1879.

${ }^{51}$ Entre los establecimientos de primera destacan los de Alcalá de Henares, Cartagena Ceuta y Valladolid. Seguidamente, los centros de segunda eran conformados por los de Burgos, San Agustin y San Miguel de los reyes de Valencia y Zaragoza. Finalmente, los de tercera eran los de Palma de Mallorca, Granada, Santoña, Sevilla y Tarragona. Véase artículo 4 Real Decreto de 1 de septiembre de 1879.

${ }^{52}$ Para estos penados se reservaban los centros de Alhucemas, Ceuta, Chafarinas, Melilla y Peñón de la Gomera. Artículo 4 Real Decreto de 1 de septiembre de 1879. Fuente: fondo documental del Instituto Nacional de Estadística, Reseña geográfica y estadística de España 1888, establecimientos penales.

${ }^{53}$ Reformas penales posteriores a destacar fueron el Real Decreto de diciembre de 1886, por el que aquellos penados mayores de 70 años, los ciegos o quejados de "cualquiera otra inutilidad de importancia á quienes no puedan aplicarse el mismo régimen penal que á los individuos en perfecto estado de salud" y los enfermos crónicos e incurables, habrían de extinguir su condena en el exconvento de Victoria, en el Puerto de Santa María. Asimismo, se ordenó la construcción de un Manicomio penal en Madrid para la reclusión de los "delincuentes afectados de cualquier forma de enajenación mental, y á la observación de todos los acusados presuntamente locos, siempre que los Tribunales de justicia decretaren esta clase de informaciones".
} 
"Porque seamos claros: teniendo la ración segura, cubiertas sus más urgentes necesidades y sin tener que pagar contribución, ni locales, ni otras muchas cosas, hacen la obra mucho más barata y se aprovechan de ella la mayoría de los industriales, con gran perjuicio de los obreros y del progreso de la industria. Nuestro parecer es que, si en los presidios no los quieren tener holgando, cuando menos que las obras que alli se trabajen sean para las necesidades de los mismos establecimientos -ó para el ejército, y de esa manera se evitarían muchos abusos" $" 54$.

Para 1884 el porcentaje de penados mostraba una clara incidencia de la delincuencia masculina, representando ésta un 95,24\% enfrente al 4,76\% de la delincuencia femenina. La mayor franja de edad con representación en los establecimientos penales era la de los penados de entre 20 y 40 años, quienes representan un 70,44\% del total de la población penitenciaria, hecho que se replica en las estadísticas judiciales. De entre los reclusos de 1884 un elemento destacable refiere a la instrucción de los reos: si bien el mayor índice es de aquellos que no saben leer $(46,44 \%)$ a ésta le sigue muy de cerca la de aquellos que efectivamente sabían leer y escribir $\left(45,48 \%{ }^{55}\right)$, elemento que habrá de ser discutido en el segundo volumen de este estudio. Por lo que al estado civil refiere, es en el grupo de solteros donde se halla el mayor volumen de penados $(49,78 \%)$.

Elemento esencial para el presente análisis es la relación entre los penados y su profesión y oficio en el momento de la comisión delictiva. Es muy interesante evidenciar que aquellos categorizados como "sin oficio" muestran índices delincuenciales muy escasos, sumando un escaso 4,26\% sobre el total de la población penitenciaria. Mayor aún es la contraposición con el pensamiento imperante cuando se evidencia que aquellos categorizados como "vagos" muestran un irrisorio $0,75 \%$ frente al grupo con mayor incidencia delictiva, aquellos dedicados a trabajos agrícolas, quienes suman un 40,53\% seguidos por los trabajadores en oficios de fuerza $(17,34 \%)$. La menor tasa de delincuencia la constituye el grupo de los eclesiásticos $(0,06 \%)$. Estos datos vienen a coincidir los pocos grupos del Cuestionario que han referido estadísticas de criminalidad. Si bien la Comisión Provincial de Valencia refiere a datos judiciales y no a datos penitenciarios debe subrayarse la coincidencia, por cuanto se establecía que, pese a la falta de datos alegada por la Comisión valenciana, las cifras facilitadas por los Juzgados de la Capital y varios municipios, y tomando un quinquenio como lapso de tiempo, la proporción de delincuencia según oficio daba un total de un $57 \%$ de trabajadores agrícolas frente a un $16 \%$ de obreros industriales ${ }^{56}$.

\footnotetext{
${ }^{54}$ Reformas Sociales, Tomo IV op.cit., p. 426-427.

${ }^{55}$ Fondo documental del Instituto Nacional de Estadística, op.cit.

56 “La relación de la delincuencia dentro de cada grupo industrial no puede conocerse por falta de datos; sin embargo , según los facilitados por esta Audiencia (que procede de los cuatro Juzgados de la capital
} 
De nuevo refiriéndonos a datos judiciales, en términos estadísticos resulta imprescindible destacar la labor realizada por la Memoria de la Comisión Provincial de Ávila, en la que puede observarse un detallado desglose acerca de las condiciones individuales de los individuos enjuiciados, donde se evidencia una tendencia similar a la expuesta: una mayor presencia de hombres $(94,7 \%)$, que no sabían leer ni escribir y donde la mayor población reclusa tenía como profesión ser jornalero $(38,27 \%)^{57}$. A su vez la franja de edad con mayor representación es la dispuesta entre los veinticinco y los cuarenta años $(34,8 \%)$. La disposición por edades es reflejada también en Bilbao donde se expone que el obrero vizcaíno, al cumplir los veintiocho años, muestra un evidente descenso en actitudes viciosas.

\subsection{Estadísticas judiciales y de criminalidad}

Como se ha referenciado anteriormente, la respuesta general acerca del último punto de la pregunta 52 del Cuestionario, delincuencia y relación, dentro de cada grupo industrial, entre el número de delincuentes y el total de la clase, suele ser que se adolece de una falta general de datos ${ }^{58}$, hecho que convierte en sumamente dificultoso, cuando no, imposible, dar una respuesta concluyente a la pregunta. Empero, sí pueden bosquejarse rasgos de las características del delincuente en el último cuarto del siglo XIX completando y contraponiendo las respuestas del Cuestionario con los datos obtenidos para el citado período (1883-1885). En primer lugar, como se infiere de los datos obtenidos por Madrid, se evidencia un tema de especial interés: la parcialidad de las estadísticas criminales. La moralidad y la legalidad de las clases acomodadas definen los ritmos y paradigmas de la delincuencia del obrero, eminentemente de carácter patrimonial. Apunta Robles Muñoz en su análisis acerca de la condición moral de los obreros en el Cuestionario como toda la estructura de justicia es contraria a los obreros $^{5960}$. Si se procede al análisis de las estadísticas judiciales entre 1883 y 1885 es claro que los delitos contra el patrimonio (denominados "contra la propiedad") constituyen en el grupo con mayor incidencia presentando el 43,89\% del total de delitos

y los de Alberique, Carlet, Chelva, Chiva, Liria, Requena, Sagunto, Sueca, Torrente y Villar del Arzobispo), tomando como regulador un quinquenio, resulta la delincuencia en proporción a la siguiente: un 16 por 100 de delincuentes industriales; un 29 por 100 de labradores, y un 28 por 100 de jornaleros de todas clases, entre los cuales la mayoría pertenecen a las labores del campo" (Reformas Sociales, Tomo III, op.cit., p. 86-87).

${ }^{57}$ Reformas Sociales, Tomo IV, op.cit., p. 314.

58 Ejemplo de ello es que El Ateneo Sueco del Socorro reconoce en su informe carecer de datos estadísticos "para poder consignar la delincuencia dentro de cada grupo industrial, sólo puede contestar que el número de delincuentes de esta villa es siempre muy reducido". Reformas Sociales, Tomo III, op.cit., p. 369.

${ }^{59}$ RoBles MuÑoz, C., "La condición moral de los obreros en los informes de la Comisión de Reformas Sociales, 1884-1886”, Revista de Política Social, no 42, 1984, p. 79-109. 
registrados en 1883, el 41,87\% en 1884 y el 41, 67\% en 1885. En la tabla siguiente se detallan los porcentajes por Título del Código Penal vigente en el momento de realización del Cuestionario:

Tabla 2. Evolución porcentual del volumen de delitos por categoría. 1883-1885

\begin{tabular}{|c|c|c|c|}
\hline & 1883 & 1884 & 1885 \\
\hline Contra la seguridad exterior del Estado & $0 \%$ & $0 \%$ & $0 \%$ \\
\hline Contra la Constitución & $0,30 \%$ & $0,63 \%$ & $0,63 \%$ \\
\hline Contra el orden público & $6,10 \%$ & $6,21 \%$ & $7,04 \%$ \\
\hline Falsedades & $2,45 \%$ & $2,60 \%$ & $2,72 \%$ \\
\hline $\begin{array}{c}\text { Inhumaciones, violación de sepulturas y salud } \\
\text { pública }\end{array}$ & $0,13 \%$ & $0,09 \%$ & $0,09 \%$ \\
\hline Juegos y rifas & $0,34 \%$ & $0,13 \%$ & $0,10 \%$ \\
\hline $\begin{array}{c}\text { Empleados públicos en el ejercicio de sus } \\
\text { cargos }\end{array}$ & $1,32 \%$ & $1,18 \%$ & $1,24 \%$ \\
\hline Contra las personas & $39,07 \%$ & $40,07 \%$ & $38,70 \%$ \\
\hline Contra la honestidad & $1,10 \%$ & $1,23 \%$ & $1,37 \%$ \\
\hline contra el honor & $1,40 \%$ & $1,61 \%$ & $1,56 \%$ \\
\hline Contra el estado civil de las personas & $0,02 \%$ & $0,04 \%$ & $0,02 \%$ \\
\hline Contra la libertad y seguridad & $1,85 \%$ & $1,70 \%$ & $1,85 \%$ \\
\hline Contra la propiedad & $43,89 \%$ & $41,87 \%$ & $41,67 \%$ \\
\hline Imprudencia Temeraria & $1,77 \%$ & $2,20 \%$ & $2,76 \%$ \\
\hline Quebrantamiento de sentencias & $0,22 \%$ & $0,34 \%$ & $0,21 \%$ \\
\hline
\end{tabular}

Fuente: Elaboración propia a partir Anuario estadístico de 1888 del Instituto Nacional de Estadística (INE)

De entre cuantas referencias se realizan en el Cuestionario acerca de la delincuencia, cabe destacar la Memoria de la Comisión local de Alcoy. En ella se refiere lo siguiente:

"Tampoco hay delincuencia, siendo el asombro de los Sres. Jueces que regentan nuestro juzgado el ver que raramente caen en sus manos hechos punibles ante la ley, no pudiendo por la misma carencia de culpables hacer a estadística que la pregunta reclama". ${ }^{2}$

No habiéndose hallado estadísticas concretas de la ciudad valenciana para el período analizado, imposibilitándose así la posibilidad de refutar o confirmar la afirmación expuesta, sí pueden ser expuestas de presente las estadísticas de la Audiencia de lo Penal de la Provincia a la cual pertenece, Alicante. De este modo, contra la pretendida

${ }^{61}$ Infracción de las leyes sobre inhumaciones, violación de sepulturas y contra la salud pública.

62 Reformas Sociales, Tomo IV, op.cit., p. 59. Empero, la información recogida por Alcoy puede presentar un claro sesgo, habiéndose presentado tales resultados ante los propios jueces. 
inexistencia criminal de Alcoy, en 1883 Alicante se constituía como la séptima provincia con mayor incidencia delictiva. Caso análogo ocurre con Ferrol, que imputa a sólo un $2 \%$ el "contingente que arroja la clase trabajadora como pasto á la estadística criminal" $^{63}$. Del mismo modo, en la Sesión de 24 de octubre de 1884 realizada en Alcira también se reputa escasa incidencia criminal ${ }^{64}$. En la línea de Alcoy se encuentra la Memoria de la Comisión Provincial de Burgos, refiriendo una criminalidad de grado mínimo y el Ferrol, donde se aduce reportar tan solo un $2 \%$ de delincuencia perpetrada por la clase obrera ${ }^{65}$.

Por lo que a las características socioeconómicas del delincuente y el reo refiere, los datos obtenidos, como ya se ha aventurado en líneas precedentes, destaca la respuesta ofrecida por la Comisión Provincial de Valencia por la que se llega a una proporción de un $57 \%$ de trabajadores agrícolas frente a un $16 \%$ de obreros industriales que han cometido actos tipificados como ilícitos penales. Sin embargo, cuando se procede al análisis detallado de los delitos cometidos atendiendo a la clasificación en grupos de trabajo o profesión en el Censo de 1877, se evidencia lo siguiente:

\section{Gráfico 1. Clasificación en grupos de Trabajo o profesión en el Censo de 1877}

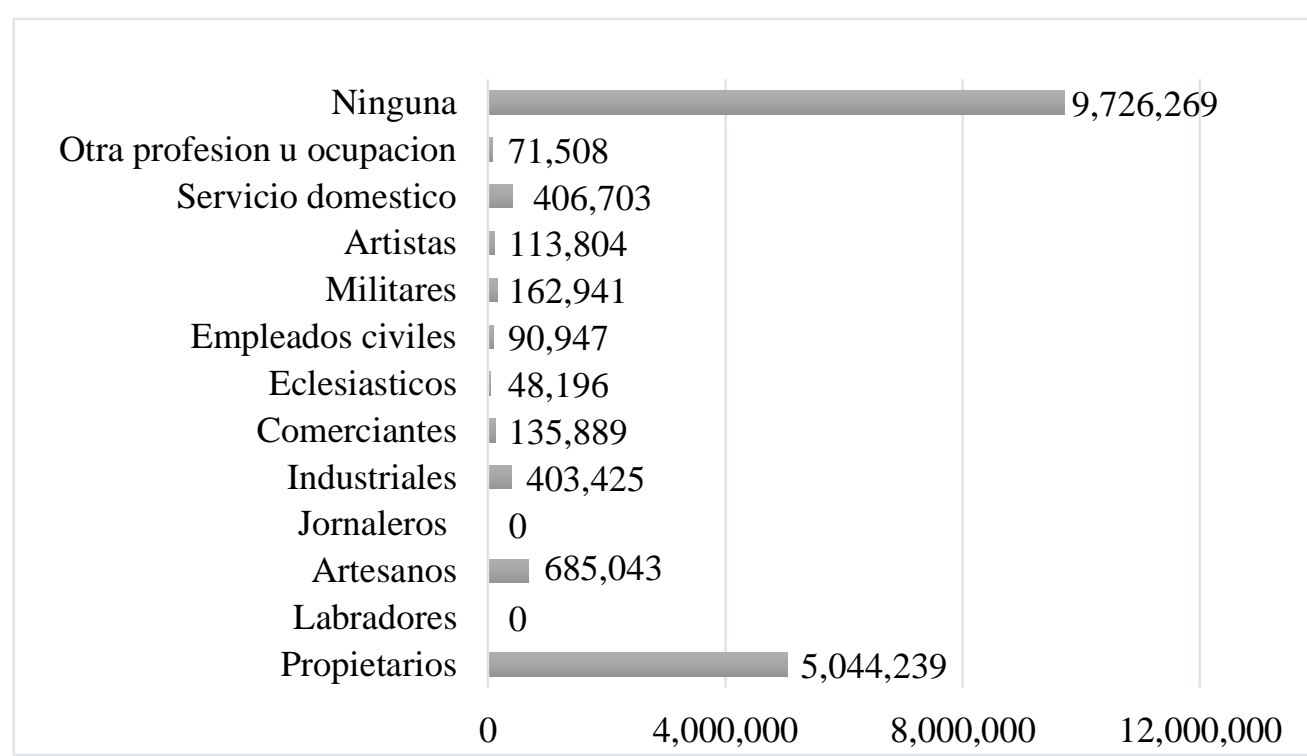

Fuente: Elaboración propia a partir del Anuario estadístico de 1888 del Instituto Nacional de Estadística (INE)

\footnotetext{
${ }^{63}$ Reformas Sociales, Tomo V, op.cit., p. 123.

${ }^{64}$ Reformas Sociales, Tomo III, op.cit., p. 285.

${ }^{65}$ Reformas Sociales, Tomo V, op.cit., p. 123, 374. Asimismo, es de especial mención el reporte de datos judiciales ofrecidos por la Audiencia Territorial de Cáceres. Reformas Sociales, Tomo IV, op.cit., p. 520 521.
} 
La contraposición de los datos presentados en la tabla ut supra y los previamente anunciados cuando hablábamos de estadísticas penitenciarias muestran una sorprendente diferencia: labradores y jornaleros no presentan valor alguno. ¿A qué puede deberse? Si se procede a analizar la clasificación con mayor número de casos se advierte que es la categorizada como "desocupados", ello permite deducir que probablemente aquellos dedicados al sector agrícola se encuentren dentro de dicha franja, no habiéndose inscrito en el censo debidamente. Esta afirmación puede ser corroborada en parte por la información obtenida de la Memoria de la Comisión de Plasencia que, pese alegar carecer de datos suficientes para relacionar la delincuencia dentro de cada grupo industrial, afirma poseer motivos suficientes pata afirmar que la mayor incidencia se presenta en el grupo de los obreros, por ser una clase numerosísima, y porque sus circunstancias y situación favorecerían la comisión delictiva ${ }^{66}$.

Pero ¿cuáles son las causas que empujan al obrero a delinquir? ¿Por qué esta distinción entre el obrero urbano y el labrador o jornalero? Es necesario hacer referencia en este punto al Informe de la ponencia de los señores de la comisión de La Coruña:

"Parecerá algo descarnado mi lenguaje, pero me he propuesto rendir culto á la verdad sin consideraciones hipócritas, que tienen siempre el inconveniente de aplazar los remedios dejando que se muera el enfermo por no diagnosticarlo á tiempo; así es que al tratar de la cultura moral del obrero entre nosotros, tiene que ser necesariamente el reflejo de lo que es la sociedad general en que vivimos, que por desgracia adolece de bastantes vicios, sostenidos por el lujo y el desmedido afán de querer llegar en poco tiempo á ser aquello que sólo puede lograrse con fuerza de años, de constancia, de trabajo y de economía, y de aquí que la prostitución y la delincuencia tengan que estar en relación con las costumbres públicas, que reclaman pronta y saludable modificación para encaminarlas por derroteros á que deben aspirar los Gobiernos y todos los ciudadanos honrados" $"$.

A medida que avanzaba el siglo XIX el crimen se fue transformando en una rotura, no tan solo del pacto social, sino de las normas de la moral, en otras palabras, de lo que era o no correcto o aceptable ${ }^{68}$. El positivismo decimonónico trataría de recogerlas en

\footnotetext{
${ }^{66}$ Reformas Sociales, Tomo IV, op.cit., p. 528.

${ }^{67}$ Reformas Sociales, Tomo V, op.cit., p. 528.

${ }^{68}$ En 1938 Robert MERTON en "Anomie and social structure" postularía una de las principales teorías criminológicas con ideas muy parecidas a las expuestas. El autor resume la idea de la criminalidad y su fundamento en la importancia en exceso que los individuos atribuyen a los logros o fines que éstos deben alcanzar puede conllevar el hecho que quien carezca de medios lícitos para su consecución llegue a
} 
factores bien sociales o bien antropológicos. No siendo objeto de este estudio entrar a detallar las teorías sobre el origen de la criminalidad en la España del ochocientos si resulta necesario incidir en determinados aspectos a fin de dar respuesta e interpretación a las respuestas obtenidas por el Cuestionario. En el ámbito penalista del período objeto de análisis toma importancia la inteligibilidad natural ${ }^{69}$, es decir, la propensión natural a la comisión delictiva, dejando a un lado otras variables tales como la intencionalidad. Sería la época de las teorías biológicas, que, de la mano de Cesare Lombroso otorgarían al criminal unos rasgos predefinidos y un potencial criminal derivado de la propia naturaleza del sujeto criminal. Se abandonan las tesis primigenias de Beccaria y Bentham que establecían el crimen como una elección racional del individuo. El delincuente delinque porque está destinado a hacerlo, es su propia naturaleza la que lo empuja al ilícito.

Empero, la teoría reflejada en el informe de La Coruña apunta a un aspecto distinto, a un "desmedido afán" de querer el criminal llegar a lujos que llevan décadas de esfuerzo a otros. En esta misma línea se sitúa la ya referida aportación del Informe del clero de Santa María, en Alicante, que atribuía la bajeza moral de la clase obrera a la ausencia de fe, hecho que convierte la frustración del obrero en actitudes inmorales e incluso delictivas y demás elucubraciones acerca del origen de la ausencia de moral, vicio y criminalidad en la clase obrera siguen esta línea de pretendida frustración entre posibilidades y objetivos, de entre los que destaca el Informe de la Comisión Provincial de Cáceres:

"Lo mismo los altos que los bajos no se satisfacen con lo que poseen, ambicionan todavía más y más, sin poner un freno ó límite á sus pretensiones. Este fenómeno, que se observa en el individuo como en la colectividad, conduce necesariamente á quererse sobreponer los unos á los otros. De ahí que una de las causas que determinan el malestar del obrero y en general de la clase proletaria, que imprime en él cierto descontento, modificando la condición moral del mismo, haciéndole ó empujándole á adoptar esas resoluciones extremas, es el mal ejemplo dado por las otras clases mejor acomodadas" 70 .

Culpan desde Cáceres al farisaico e hipócrita proceder de las clases favorecidas, quienes propugnan el acometimiento de actuaciones para mejorar la condición de la clase

emplear la delincuencia para conseguir su logro. Véase MERTON, R. K., "Social structure and anomie", American sociological review, $\mathrm{n}^{\circ} 3.5,1938, \mathrm{p} .672-682$.

${ }^{69}$ JiMÉNEZ AlONSO, B., La construcción psico-sociológica de la "subjetividad marginal" en la España de finales del siglo XIX y principios del XX, Tesis doctoral, Facultad de Psicología de la Universidad Nacional de Educación a distancia, Madrid, 2010.

${ }^{70}$ Reformas Sociales, Tomo IV, op.cit., p. 462-464. 
obrera, invocando a la instrucción como medio principal, pero pecando en la exhibición del lujo "en los trajes, en los trenes, en las cómodas viviendas, y el derroche de fortuna para satisfacer todos los caprichos y todos los apetitos"71.

\section{Conclusiones}

Los vicios en la condición moral de la clase obrera de la España del último cuarto del siglo XIX describen una imagen similar en todo el territorio objeto de estudio. Las principales variables que inciden en la comisión de actos considerados como faltos de moral son, esencialmente, la miseria en la que vivía sumida la clase obrera y una acuciante necesidad de supervivencia. Claro ejemplo de ello es el primero de los vicios reseñados, la embriaguez. Al margen de las críticas operadas por las clases pudientes, el obrero recurre principalmente alcohol para evadirse de la realidad que se esconde entre los muros de la fábrica. Mecanismo similar es el que empuja al obrero al juego y, de modo flagrante, empuja a las jóvenes a la prostitución. Este trabajo trata actos que se contraponen con el orden moral imperante de una sociedad regida por estrictos dogmas influenciados por la moral católica que condenan actuaciones tales como el concubinato, fruto, nuevamente, de la escasez de recursos en la que vive sumida la clase obrera. Los vicios, en muchos de los casos reportados, son fruto de la ignorancia y la falta de instrucción.

Mayor atención requiere el estudio de la delincuencia perpetrada por la clase obrera. Como ya se ha referido, la ausencia de datos estadísticos se constituye como el primer obstáculo a sortear para lograr un análisis pormenorizado. Empero, la reiterada referencia al obrero delincuente como alguien que opta por la criminalidad en una inmoral búsqueda del lujo que no puede alcanzar por medios lícitos permite ilustrar la cuestión social. ¿Es, en efecto, la delincuencia, fruto de la desilusión y el fracaso del obrero o estamos bosquejando una imagen sesgada proferida por quienes desconocen de la ventura de quienes viven entre los muros de la industria o dedicados a las duras tareas del campo?

Por todo ello, sirviendo el presente trabajo como primera parte del análisis de la virtud y los vicios en la moral del obrero, deberá ser completado con un posterior estudio acerca de la virtud y las propuestas recogidas en los Informes acerca de cómo proceder a enmendar las situaciones descritas en estas páginas.

\section{Bibliografía}

ALbÓ, R., “La prostitución de los niños”, Proinfantia, n 155, Madrid, 1924.

\footnotetext{
${ }^{71}$ Reformas Sociales, Tomo IV, op.cit., p. 463.
} 
Álvarez, J., "La Comisión de Reformas Sociales: Intentos y realizaciones", De la beneficencia al bienestar social. Seminario de Historia de Acción Social, Madrid, Consejo de General de Colegios Oficiales de Diplomados en Trabajo Social y Asistentes Sociales, Editorial Siglo XXI, 1986.

CAstillo, S., "El reformismo en la Restauración: Del Congreso Sociológico de Valencia a la Comisión de Reformas Sociales"; Estudios de Historia Social, no 30, 1984, p. 21-78.

CAMPOS MARín, R., "La Sociedad enferma: higiene y moral en España en la segunda mitad del siglo XIX y principios del XX”, Hispania, Tomo 55, no 191, 1995, p. 10931112.

de la Calle Velasco, Mª D., La Comisión de Reformas Sociales 1883-1903: política social y conflicto de intereses en la España de la Restauración, Centro de publicaciones del Ministerio de Trabajo y seguridad Social, Madrid, 1989.

DE la Calle Velasco, Ma D., "La Comisión de Reformas Sociales: de la represión al análisis de la conflictividad social”, Studia Historica, vol. II, nº4, 1984, p. 13-41.

DíAZ DE RUEDA, R., La Escuela de Instrucción primaria, Impr. De Cuesta y Compañía, Valladolid, 1855.

Duran VentosA, R., L’ivresse devant le Droit Penal, Imprenta A. López, Barcelona, 1890.

ElorZA, A. y Iglesias, M C., Burgueses y Proletarios. Clase obrera y reforma social en la Restauración (1884-1889), Editorial Laia, Barcelona, 1973.

Elorza, A. y IGlesias, M ${ }^{a}$ C., "La fundación de la Comisión de Reformas Sociales", Revista de Trabajo, nº 25, 1969, p. 75-105.

Espuny ToMÁs, M. J., "Fisiología i moral en la legislació social", Agor@2000: Jornades per la igualtat $d^{\prime}$ oportunitats $i$ responsabilitats a la vida laboral $i$ familiar. Barcelona, Generalitat de Catalunya, Institut Català de la Dona, 2001, p. 131-141.

FreIXA, F., "Perspectiva histórica de la problemática del alcohol en España", en TORRes Hernández, M. A. (Coordinador) et al., Historia de las adicciones en la España contemporánea, Gobierno de España, Ministerio de sanidad y consumo, 2009, p. 171-187. 
GAVILÁn Rubio, M., "Delitos relativos a la prostitución y a la trata de seres humanos con fines de explotación sexual. Algunas dificultades en la fase de instrucción”, Anuario Jurídico y Económico Escurialense, vol. XLVIII, 2015, p. 103-130

JiMÉNEZ AlONSO, B., La construcción psico-sociológica de la "subjetividad marginal" en la España de finales del siglo XIX y principios del XX, Tesis doctoral, Facultad de Psicología de la Universidad Nacional de Educación a distancia, Madrid, 2010.

Martínez Montalvo, M. C., "La elaboración del vinagre en el siglo XIX. Discordia y enfrentamiento químico-biológico", Historia de las ciencias y de las técnicas, vol. 2, 2004, p. 687-702.

MAyordomo, A., "Bases para el estudio de la formación moral y de la civilidad a través de los textos escolares en la primera mitad del siglo XIX", Historia de la Educación, vol. 2, 1983, p. 55-65.

MERTON, R. K., "Social structure and anomie", American sociological review, $\mathrm{n}^{\mathrm{o}} 3.5$, 1938, p. 672-682.

Palacio Morena, J. I., La institucionalización de la reforma social en España (18831924). La Comisión y el Instituto de Reformas Sociales, Madrid, Ministerio de Trabajo y Seguridad Social, 1988.

Pascual Pastor, F., “Antecedentes históricos de las Adicciones. Del siglo XIX hasta 1940”, en Torres Hernández, M. A. (Coordinador) et al., Historia de las adicciones en la España contemporánea, Gobierno de España, Ministerio de sanidad y consumo, 2009, p. 13-35.

PAZ, O. y CASAS, L., "Presidio, castigo, prostitución: mujeres en el siglo XIX", Crítica Penal y Poder, $\mathrm{n}^{\circ}$ 15, 2018, p. 150-179.

Reformas Sociales, Información oral y escrita publicada de 1889 a 1893 . Edición al cuidado de Santiago Castillo. Edición facsímil. Centro de Publicaciones Ministerio de Trabajo y Seguridad Social, Madrid, 1985.

Robles MuÑOZ, C., "La condición moral de los obreros en los informes de la Comisión de Reformas Sociales, 1884-1886”, Revista de Política Social, n 42, 1984, p. 79-109.

SÁEZ MARTíNEZ, G. J., “Aproximación histórica a los abusos sexuales a menores”, en Eguzkilore, no 29, 2015, p. 137-170. 
SANTAMARÍA LAMBÁs, F., El proceso de secularización en la protección penal de la libertad de conciencia, tesis doctoral, Universidad de Valladolid, 1999.

SuÁrez CASAÑ, V., La prostitución, Casa editorial Maucci, Barcelona, 1895. 